\title{
MARJANE SATRAPI. LA ARTISTA QUE REDIBUJÓ IRÁN
}

\section{MARJANE SATRAPI. THE ARTIST WHO REDRAW IRAN}

\author{
Elena Pérez Elena \\ Universitat Jaume I de Castellón
}

\section{RESUMEN}

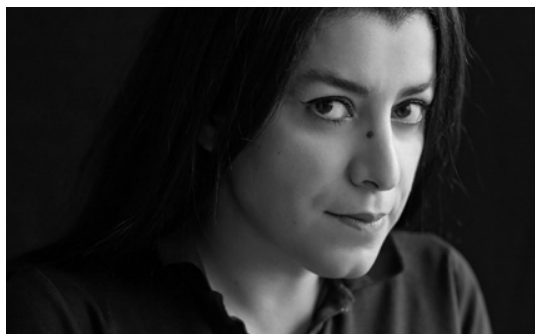

Persépolis, la novela gráfica autobiográfica de la artista iraní Marjane Satrapi, muestra cómo era la vida en el Irán en el que vivió Marjane, contando las historias de la historia, recuperando las voces silenciadas en la sociedad iraní. Satrapi, no sólo relata, como testigo, los acontecimientos históricos transcurridos en su país sino que también revela con detalle la situación de la mujer en Irán-deshaciendo posibles estereotipos por parte de los y las occidentales- al tiempo que descubre cómo va forjándose su propia identidad. Una identidad que ella misma puso en tela de juicio al vivir en un mundo dual lleno de restricciones y de privación de libertades que le hizo dudar de quién era ella como mujer, como ciudadana y como persona.

Palabras clave: Marjane Satrapi, Persépolis, Irán, mujer, novela gráfica.

\section{ABSTRACT}

Persepolis, the autobiographical graphic novel written by the Iranian artist Marjane Satrapi, shows how was life in the Iran where Marjane lived, telling the stories of the History, recovering the silenced voices in the Iranian society. Satrapi not only recounts, as a witness, the historical events happened in her country, but also reveals, in detail, the women's situation in Iran -undoing possible stereotypes by Westerners- while she discovers how her own identity is been created. An identity that she questioned while living in a dual world full of restrictions and deprivation of freedom that made her doubt about who she was as a woman, as a citizen and as a person. Keywords: Marjane Satrapi, Persepolis, Iran, woman, graphic novel. 
Desafiar la historia, las convenciones sociales y transgredir las normas con el objetivo de luchar por la libertad y la igualdad es una tarea ardua, difícil y, en muchos casos, peligrosa. Los problemas se multiplican cuando esa persona transgresora es una mujer y se encuentra en un contexto de intolerancia y sumisión. Cuando una mujer, en su trayectoria vital, lidia con estas circunstancias para seguir adelante, luchando por sus derechos contra lo políticamente correcto, denunciando las injusticias y la tortuosa realidad que está viviendo, está llevando a cabo un desafío abierto contra el sistema en el que vive. Estos actos requieren valentía, requieren coraje, y la multidisciplinar artista iraní Marjane Satrapi es un claro ejemplo de mujer coraje.

Marjane Satrapi es una artista de novela gráfica nacida en Rasht (Irán) el 22 de noviembre de 1969, tan sólo diez años antes de que se produjera la Revolución Islámica en 1979 y, por tanto, testigo de cambios trascendentales en el devenir de la historia de su país que repercutieron de manera determinante en la sociedad iraní con la implantación de la todavía vigente República Islámica de Irán. La familia Satrapi, no obstante, no se puede tomar como ejemplo paradigmático de familia iraní pues la artista se crió en el seno de una familia, siendo ella hija única, con poder adquisitivo y con una ideología progresista que marcó su desarrollo personal al hacer especial hincapié en la importancia que tenía para su futuro la educación, privilegio al que no todas las mujeres iraníes tenían y tienen acceso. Y, aunque cursó los estudios primarios en su país de origen, sus padres, en busca de una mayor libertad para su hija y huyendo de la represión y del oscurantismo que se había apoderado de Irán, la enviaron a acabar la educación secundaria a Europa, concretamente a Viena. Sin embargo, Marjane retornó a su país para cursar los estudios universitarios, matriculándose en Bellas Artes en la Universidad de Teherán, realizando también allí el máster de Comunicación Audiovisual. No obstante, la censura, la opresión y la continua sumisión de la mujer al hombre y a los predicados del islam más sombrío y retrógrado condujeron a Marjane a tomar la decisión de exiliarse a Francia, primero a Estrasburgo donde estudiaría Artes Decorativas para más tarde acomodarse en París. Francia, país del que a día de hoy ha hecho su nuevo hogar, obteniendo la nacionalidad francesa.

Marjane, artista iraní, mujer coraje, ha querido dar voz a las voces silenciadas que la historia en mayúsculas no recoge, a través de su opera magna, Persépolis, una novela gráfica autobiográfica publicada en cuatro entregas entre los años 2000 y 2003, recopilada más tarde en un único volumen. En ella ha tratado de hacer llegar a Occidente la realidad que la artista y la sociedad iraní han vivido en ese país contando la «verdad respecto a la vida», término que acuñó el filósofo estadounidense John Hospers (Hospers, 1980: 210), y no únicamente como «realidad respecto a los hechos». Al ser ella misma consciente de los posibles 
prejuicios que pueden llegar a tener los occidentales hacia los y las iraníes y el desconocimiento hacia su país -algo que hace notorio en las últimas viñetas de su memoria gráfica cuando su alter ego dibujado aparece rodeado de personas que le formulan preguntas estereotipadas como «jes que en Irán todo el mundo es terrorista? ¿ ¿es verdad que allí las mujeres

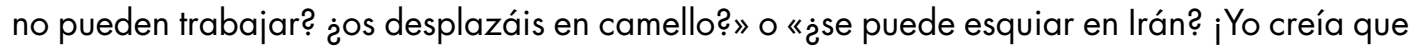
sólo había desierto!» (Satrapi, 2010: 361)- ha querido plasmar en papel su autobiografía haciendo coincidir su tiempo interno con un momento crítico en la historia contemporánea de Irán: las manifestaciones y revueltas de la población contra el régimen del shah Mohammad Reza Pahlaví, la Revolución Islámica, que dio lugar al nacimiento de la República Islámica de Irán, y las consecuencias que tuvo. Una memoria gráfica cuyo final estaba realizado para que coincidiese con el exilio de Satrapi a Francia en los años 90.

Marjane, con ello, no sólo ha querido plasmar los principales acontecimientos de este período histórico, sino que ha pretendido ir más allá, dejando testimonio de cómo ello afectó a la población, poniendo ejemplos concretos, ejemplos reales que ella misma vivió en persona con tal de transmitir al mundo el sufrimiento de los y las iraníes. Un sufrimiento al que siente que Occidente parece ser inmune, estar acostumbrado y al que ella reclama atención e intenta despertar mostrando la pura realidad; una realidad que en muchas ocasiones parece que se haya olvidado: los medios de comunicación tienen el poder de mover masas o de hacerlas sumisas vendiendo la visión del mundo que más convenga a los interesados. Ella misma afirma de manera contundente que «Demasiada información bloquea el cerebro, poca nos hace ignorantes. Pero lo peor es la información unidireccional» (Satrapi, 2010: 362) y parece que en Occidente siempre impera una única voz convirtiéndose en un problema. Muchas veces se piensa que sólo hay una única manera de ver las cosas y ésta es a la que los medios de comunicación acostumbran, olvidando lo que realmente importa. El norte se ha perdido: la paz no es propiedad de Occidente, tal y como dice Marjane:

¡Como si la gente adorase morir en explosiones! ¡Como si vivir en paz fuese el privilegio de una parte del mundo! Hoy en día en Irán, centenares de estudiantes, periodistas e intelectuales permanecen en prisión por haber soñado con la libertad. ¡Eso tampoco os lo han contado! No es grave, creedme. Uno se acostumbra a todo. (2010: 366).

Toda esta frustración, todas esas ganas de la artista de denunciar las injusticias, la crueldad y la privación de libertades que había presenciado en su país en primera persona necesitaba encontrar una vía de salida y, la herramienta para poder llevarlo a cabo, el elemento canalizador, ha sido el cómic. La novela gráfica autobiográfica como vehículo de denuncia. Su testimonio convertido en arte. 
Este medio, aparentemente poco convencional, ha servido a Satrapi y a otros jóvenes creadores para poder plasmar contundentemente el desgarro interior de la realidad que han vivido. $Y$ es que en los últimos tiempos el modo de hacer historia y de denunciar la realidad está cambiando, convirtiéndose el cómic en un magnífico género complementario, que no sustitutivo, de la historia en mayúsculas, permitiendo al lector adentrarse en los más profundos sentimientos del autor o autora además de en los personajes, los casos particulares, permitiéndose empatizar con ellos. Esta conexión tan personal que se produce entre emisor y receptor, entre receptor y mensaje, es inherente a esta forma de expresión, a este arte, es algo que va implícito en él. Se produce una suerte de magia que permite, con tan sólo un golpe de vista, introducir al lector de lleno en el cómic, en sus viñetas, que cobran vida y movimiento en sus cabezas, formándose una retahíla de imágenes que fluyen trasladándolos espaciotemporalmente a su interior, a su historia. De hecho, se trata de un «arte monosensorial» (McCloud, 2005: 89) que significa que, gracias a los recursos que se han utilizado a la hora de confeccionar las viñetas, el lector y la lectora son capaces de experimentar sensaciones correspondientes a todos los sentidos con tan sólo el sentido de la vista.

Pero, antes de ahondar en el por qué la artista apostó por este soporte para denunciar la realidad, se debe ser consciente de que el cómic ha ido sufriendo cambios hasta convertirse en lo que hoy se conoce como novela gráfica -a la que me referiré como memoria gráfica en los casos en los que ésta primera sea autobiográfica al considerar que es un término muy acertado y que ya venía indicado en la contraportada de la novela gráfica autobiográfica por antonomasia Maus (1973-1991) de Art Spiegelman.

A menudo el cómic ha sido considerado una mera antesala al arte en mayúsculas, un fruto de la sociedad de consumo e incluso un híbrido entre dibujo y literatura. Sin embargo, el cómic ha demostrado ser un arte en mayúsculas a lo largo de toda su trayectoria haciendo ver que el problema que tenía era que lo estaban comparando con otras disciplinas cuando el cómic es cómic por sí mismo, al igual que las anteriores lo son por ellas mismas y por tanto, como indica el historietista y ensayista español Santiago García, la relación del cómic con el arte y la literatura no se puede explicar en términos comparativos sino en términos alternativos (García, 2010: 28). De hecho:

El cómic como forma artística no tiene nada de vulgar ni de infantil. Por el contrario, es sofisticadísimo. El cómic no es un híbrido de palabra e imagen, un hijo bastardo de la literatura y el arte que haya sido incapaz de heredar ninguna de las virtudes de sus progenitores. El cómic pertenece a una estirpe distinta, y se realiza en un plano diferente al que se realizan cada una de esas artes. Tiene sus propias reglas y sus propias virtudes y limitaciones, que apenas hemos empezado a entender (García, 2010: 265). 
$Y$, aunque parafraseando al filósofo italiano Formaggio diciendo que «Cómic es aquello que los hombres llaman cómic» (Jiménez, 2002: 51; cit. en García, 2010: 42) claramente este arte ha ido sufriendo una evolución con el tiempo. En el caso que expongo, el cómic que ha evolucionado a novela gráfica es el que reunía una serie de determinadas características: que se encuentre impreso, que la reproducción de la obra sea en serie y que esté dirigido a un público de masas -esta última característica es matizable especialmente en el caso de las memorias gráficas, en muchas ocasiones dirigidas a un público minoritario. Además también se puede decir que, con el tiempo, los cómics han ido cambiando el destinatario hacia quienes iban dirigidos pasando a formar parte de la lectura de un colectivo más adulto. También los cómics han tendido a aumentar su extensión -característica que no tienen por qué cumplir de manera necesaria- pero sobre todo se aprecia un gran cambio en la intencionalidad con la que han sido creados derivando especialmente hacia una intencionalidad crítica; y en la temática, donde temas tabú como el sexo o las drogas se han hecho un hueco. Todas estas nuevas matizaciones y variaciones que ha ido experimentando el cómic a lo largo de la historia es lo que han hecho que éste haya ido más allá de sí mismo y haya sido necesario un cambio de nomenclatura consecuente con los cambios que experimentaba, pasando a denominarse novela gráfica. Estas variaciones se vinieron gestando de manera más contundente desde los años 60 del siglo $X X$, década que supuso un punto de inflexión en la historia del cómic moderno con la aparición del cómix underground, rompiendo con todos los esquemas y dando nacimiento al subgénero de la novela gráfica autobiográfica. Como se ha remarcado antes, dentro de este subgénero supuso un hito en la historia la publicación en los años 80 del siglo XX de Maus de Art Spiegelman quien plasmó en este formato las atrocidades vividas por sus padres en el campo de concentración de Auschwitz a través del testimonio oral de su padre Vladek. Spiegelman supo ver una herramienta explosiva, un arma de doble filo. Tanto el artista sueco de familia de ascendencia judía polaca como Satrapi encontraron en ese medio, en la memoria gráfica, el perfecto vehículo para comunicar al lector sus vivencias, sensibilizarlos, al mismo tiempo que ellos mismos se liberaban de sus miedos, ansiedades, de un pasado que les perseguía y que necesitaban compartir al mismo tiempo que seguir conectados. Es decir, encontraron en él un medio terapéutico que les permitía que sus más profundas ansiedades y sus traumáticas experiencias fluyeran a través de la tinta y el papel, permitiendo airear los corazones, como decía la abuela de Marjane, y despojándoles un poco de la presión y el dolor por el que habían pasado, compartiéndolo con el mundo. Este es un mundo con el que los lectores llegan a desarrollar una fortísima empatía tanto hacia los personajes que aparecen en el cómic como hacia el autor o autora. Ven en ellos valores universales. Estas novelas gráficas autobiográficas siempre suelen enmarcarse en un contex- 
to de represión, de cambio, donde el ser humano debe sobreponerse a las adversidades, situaciones en las que se puede contemplar tanto lo trágico como lo sublime. Un soporte en el que sus autores no tienen miedo de plasmar las más duras atrocidades que han vivido, de manera incluso descarnada. He aquí la razón por la que estos autores, como es el caso de Marjane Satrapi, escogen la memoria gráfica para plasmar sus dolorosas vivencias: si hubieran escogido un soporte diferente como la fotografía, el cine o el documental, el espectador habría sido incapaz de interiorizar tanto dolor y sufrimiento. La realidad, su dureza, habría impedido asimilar aquello que se estaba viendo, imposible soportarlo ya que produciría repulsión, hiriendo al lector. Sería como con las noticias del telediario que, sabiendo que no se puede digerir, con tan sólo un click el espectador apaga lo que le hiere y escandaliza para regresar a «su» realidad.

Esto cambia con la memoria gráfica. Lo que la hace, a mi juicio, un soporte tremendamente poderoso para la denuncia es que al dilatarse en el tiempo la obra, los acontecimientos pueden ir siendo asimilados por el lector de manera paulatina, algo que no impide que pueda llegar a afectar anímica y fisiológicamente al lector. De hecho, esta afectación que puede llegar a producir también depende de cómo haya enfocado el cómic su autor. En él, dependiendo de la intencionalidad de quien lo concibe, se decantará por centrarse o bien en el contenido o bien en la forma. Si se apuesta por el primero, se adopta una forma simple que se pueda comprender fácilmente para que todo el peso recaiga en el mensaje. En cambio, si el autor o autora decide centrarse en la forma, el resultado será un dibujo más minucioso en el que recaerá la fuerza comunicativa. El primer caso sería el de Marjane Satrapi. Con esto quiero decir que, aunque quizá el lector se pueda estremecer de manera más rápida cuando el autor se centra más en la forma que en el contenido, ambos pueden llegar a ser muy contundentes afectando fisiológicamente al lector. Sin embargo, esa lectura dilatada en el tiempo, y al estar narrada a través de viñetas, permiten que el lector y la lectora puedan proseguir leyendo, asimilando los acontecimientos. Esta es una manera de poder conocer e interpretar -cada uno a su manera- realmente los sucesos, las realidades de los autores y de sus sociedades, pues al poder asimilar lo que narran sin apartar la vista frente al desgarro que sienten, como sí se haría al tratar de contemplarlo en una fotografía; se puede empatizar y conectar de manera más personal y concienciar realmente de lo que está sucediendo. Esto permite al lector estar preparado y mentalizado para contribuir en la lucha contra esas injusticias y ayudar a alzar su voz. Sólo siendo realmente conscientes y empatizando desde el corazón los lectores serán capaces de aportar su grano de arena a la causa, no apagando el botón de la televisión y cerrando los ojos a la realidad porque es «demasiado difícil de soportar». 
Pero como he dicho, el hacer memoria gráfica no tiene un único propósito unidireccional sino que tiene también gran importancia para el autor. En el caso de la memoria gráfica de Satrapi, ahora que ella se encuentra exiliada sin oportunidad de regresar a su país, a la tierra que le vio crecer y en la que están sus raíces, la memoria gráfica supone un hilo invisible que aún la mantiene conectada a su pasado, a quien un día fue. Es una manera de seguir unida con una parte de ella y con las personas que dejó atrás, sus recuerdos...

Un género con mucho futuro que está en plena etapa de desarrollo y al que todavía le queda mucho camino por recorrer con muchas posibilidades de experimentación al alcance de su mano. Un mundo que permite múltiples posibilidades y al que habrá que seguir la pista bien de cerca para ver cómo evoluciona y qué direcciones decide seguir. Sin embargo, hay algo para lo que no hay que esperar, y es que en el género de la novela gráfica, la mujer ha estado presente desde sus inicios, y ha encontrado en él, especialmente en el subgénero de la memoria gráfica, un lugar en el que su voz se escucha igual de fuerte que la del hombre. Muchas han sido las mujeres que han apostado por este soporte para expresarse y convertir sus ideas, sentimientos y vivencias en arte. Al contrario que en otras disciplinas, las mujeres gozan de equidad, tanto en el respeto hacia ellas como a sus obras. El género de la autobiografía se ha convertido en un género muy rico, en el que se escucha tanto a hombres como a mujeres en obras magistrales, pero ya no sólo eso, sino que se trata de un género que ha tenido éxito en Occidente pero que ha eclosionado con una fuerza brutal entre artistas procedentes de los considerados países periféricos.

Marjane Satrapi encaja en este último perfil que he trazado. Una artista de la novela gráfica autobiográfica proveniente de un país periférico como es Irán, ha plasmado en una obra magistral lo que sus ojos presenciaron en su país, al que a día de hoy no puede volver. Como ella tan bien dice al final de la obra «La libertad tenía un precio...» (Satrapi, 2010: 356).

Irán, escenario de la memoria gráfica de Marjane, hoy día República Islámica de Irán, es un territorio que ocupa una posición estratégica en el mundo y cuyos recursos, como el petróleo, han sido muy deseados y motivo de pugna y conflictos a lo largo de su historia, si bien ahora se encuentra en pleno debate en lo que respecta a la energía nuclear. País de Oriente Medio en el que el factor religioso no se puede separar en ningún ámbito de la vida, en Irán se profesa el islam más esotérico y mesiánico: la rama del islam shiíta, la que cree que algún día regresará el mahdi, el duodécimo imán. Es la religión que profesa casi el $90 \%$ de la población iraní. Irán, un país donde se acata obediencia religiosa.

Marjane cuenta la historia de su país y los acontecimientos que en él se desarrollaron desde momentos previos a la caída del shah Mohammad Reza Palahví, la Revolución Islámica, la posterior proclamación de la República Islámica de Irán, la guerra Irán-Iraq, hasta 
llegar al Irán de los años 90. Persépolis se encarga de narrar no únicamente estos acontecimientos sino también las historias de la historia, mucho más personales, que acaban por conformar la historia en mayúsculas. Pero sobre todo, en esta opera magna aparece la suya propia, cambiando de escenario cuando se marcha a estudiar a Viena y nuevamente cuando regresa. La suya, otra historia de la historia que l'Association, editorial francesa independiente, quiso que Marjane plasmara en una novela gráfica autobiográfica para dar a conocer al mundo un testimonio de incalculable valor, tal y como hizo Artie con el testimonio oral de su padre Vladek en Maus.

Para llevar esta tarea a cabo Marjane realizó la obra íntegramente en blanco y negro de principio a fin, exceptuando las páginas finales, en las que se dirige a los lectores, haciéndoles reflexionar sobre el largo camino que hay por delante para seguir deshaciendo los estereotipos que continúan alimentando los medios de comunicación occidentales hacia su país. Estas últimas páginas son las únicas de toda la obra que están en color. El blanco y negro como recurso estilístico que remite al pasado, tiempo en el que está narrada la obra otorgándola un carácter de lejanía en el tiempo, y que ayudan a centrar al lector en el contenido del mensaje que la artista quiere transmitir, siendo estos colores necesarios para tratar un tema tan peliagudo, tan delicado y tan serio. Las páginas coloreadas corresponden a un tiempo en el que Marjane ya no se encuentra en Irán, y se dirige directamente a los y las lectoras: es el momento en el que está dando por finalizada su memoria gráfica dejando espacio y tiempo para la reflexión sobre todo lo que ha narrado tras abrir su memoria y su corazón. Siguiendo en esta perspectiva estética cabe decir que estos colores tan sombríos contrastan mucho con la técnica de Satrapi para dibujar a los personajes y los espacios ya que todos tienen un aire muy naíf. Como bien decía antes, hay artistas que deciden centrarse más en el contenido, en el mensaje que deciden dar, que en la forma; este es el caso de esta obra de Satrapi, dibujos sencillos para un mensaje muy potente.

En este viaje a lo largo de su memoria gráfica, ya desde el principio, el lector y la lectora pueden apreciar cómo la artista tiene una característica manera de narrar los acontecimientos y es que para poder canalizar todo el sufrimiento por el que ha pasado y las atrocidades que ha presenciado necesita hacer uso de la ironía, pero no de cualquier manera, sino de una ironía dura, en ocasiones cínica, complementándola con la sátira y el sarcasmo. Un mecanismo de defensa que le permite poder poner sobre el papel lo que en su cabeza es insoportable. Mecanismo que ya utiliza al hablar de esos momentos de tensión previos a la tan esperada caída del shah por un amplio sector de la población iraní, que desencadenaría en la Revolución. Marjane en este período ya tenía que hacer frente a una dualidad interna entre tradición y modernidad que se incrementó de manera drástica con la llegada al país de 
Jomeiní y la proclamación de la República Islámica. Una dualidad que, tal y como muestra, va incrementando a lo largo de su vida hasta llegar el momento de no saber quién es, de negar su identidad como le ocurrió en Viena, de perder el norte.

Vivir bajo el yugo de una dictadura como la del shah, que pretendía modernizar el país a la manera occidental al tiempo que mantenía la fuerte presencia del clero y teniendo el islam shiíta por bandera, era vivir en un sistema, ultraconservador, difícil de encajar. Las reformas que llevó a cabo Reza Pahlaví no fueron bien acogidas por la población, que acabó manifestándose en su contra y Marjane, siendo tan sólo una niña, ya vivía este ambiente de tensión y represión tanto dentro como fuera de casa. Puertas hacia dentro, Satrapi veía como sus padres, de tendencia progresista, se manifestaban en contra del shah. Sus padres, convencidos al principio de que la Revolución acabaría con la dictadura y que no imaginaron que se implantaría en el poder un gobierno islamista. De hecho, fue Ebi, el padre de Marjane quien abrió los ojos de la artista acerca de la verdad sobre el régimen del shah, a quien veneraban en la escuela pues «Dios le había escogido». Satrapi siempre encontró en su familia personas que le dieron importantes lecciones que le acompañarían toda la vida y que, aún a día de hoy, lo siguen haciendo. En esta familia privilegiada, progresista y con medios fue en la que la pequeña Marii se crió y la que le dio otra visión de la realidad que estaba viviendo, una visión muy diferente de la que aprendía en la escuela. Por ello, contar con las enseñanzas de sus cuatro pilares, su padre, su madre, su tío Anouche y su abuela, le ayudaron a convertirse en la mujer que es a día de hoy.

Su padre le enseñó la importancia de ser sincera, algo que acabó por caracterizar a Marjane, pero sobre todo el valor impagable de la libertad personal, el libre albedrío para poder tomar decisiones por sí misma aunque ello supusiera equivocarse. Su segundo pilar, su madre, también le inculcó uno de los valores a los que Marjane recurría cada vez que se sentía perdida, desorientada y que le ayudaba a encaminarse: la educación. Imposible, cuando se lee y se conecta con Marii, el alter ego de Marjane en la novela que la representa cuando era niña, no recordar y establecer comparaciones con el magnífico y magistral personaje creado por el artista argentino Quino, Mafalda. Ambas avanzadas intelectualmente a su edad, con picardía, pero sobre todo niñas que se dan cuenta de lo que el resto de personas pasan por alto. En el caso de Marjane, ella encuentra en la educación, en instruirse, la brújula que le va a ayudar a guiarse en el camino, porque es la educación -un privilegio que no todos los jóvenes iraníes tienen y aún menos las mujeres- la que le ayuda a emanciparse, a conocerse a sí misma y la solución cuando perdía el rumbo «Una vez más, llegué a la conclusión de siempre: tenía que instruirme.» (Satrapi, 2010: 342). En cambio, su tío Anouche la deslumbró siendo sólo una niña con los ideales de libertad, con el comunismo -por lo que 
había sido encarcelado en el pasado-, con la lucha por los ideales, ideas que calaron en la pequeña Marii. Por último, el cuarto pilar en su vida fue la figura de su abuela, quien le dio un consejo, que junto a cada una de las enseñanzas citadas le sirvió de brújula, sólo que éste de manera especial:

Escucha, no me gusta echar sermones, pero te voy a dar un consejo que te servirá siempre. En la vida te encontrarás a muchos imbéciles. Si te hieren, piensa que es su estupidez la que les empuja a hacerte daño. Así evitarás responder a su maldad. Porque no hay nada peor en el mundo que el rencor y la venganza... Mantén siempre tu dignidad, tu integridad y la fidelidad a ti misma (Satrapi, 2010: 159).

Este consejo siempre lo tuvo presente Marjane, especialmente cuando más sola se sentía, en Viena.

Y es que la vida de Satrapi ha estado incondicionalmente unida a tres cuestiones. La primera, los turbulentos acontecimientos históricos con los que ha tenido que crecer y vivir en su país; la segunda, su condición de mujer en un país donde estaba supeditada al patriarcado y a las estrictas convicciones religiosas del islam; y por último la tercera, la crisis de identidad que vivió debido a la dualidad interna con la que tuvo que lidiar: dos mundos el progresista que vivía puertas hacia dentro y el retrógrado, controlador y prohibitivo que vivía puertas hacia fuera.

Estos tres aspectos marcaron su trayectoria vital hasta su exilio en Francia. La vida que ella plasma en su memoria gráfica no fue fácil, tan desgarradora que quizá la única manera que tenía de contarla de la manera más fidedigna era a través de este medio.

Satrapi vivió los albores de la Revolución siendo tan sólo una niña. Algunos aspectos, tal y como los narra, no los vivió de manera directa sino que los vivió a través de su entorno y los medios de comunicación -de los que debían saber sortear la fuerte censura a la que estaban, y están, supeditados. Y es que sin llegar a la edad de diez años ya tuvo que ver cómo las calles de su ciudad se estaban convirtiendo en el escenario de un campo de batalla tanto a nivel físico como a nivel emocional. La pequeña Marii documenta cómo estas manifestaciones se fueron sucediendo cada vez con más frecuencia y más afluencia de gente. Manifestaciones donde la policía secreta del régimen del shah, la SAVAK, no dudaba en intervenir como fue el caso del incendio de los cines Rex, en el que momentos antes cerraron sus puertas con la gente dentro e hicieron caso omiso de las peticiones de ayuda, atacando a todo aquél que intentara socorrer a las personas que se estaban quemando vivas en el interior del edificio ante la impasibilidad de la policía. Marjane y su familia no sólo participaron en estas manifestaciones que empezaban a preocupar a los poderosos titiriteros sino que fueron 
testigos de cómo la sociedad iraní, que reclamaba la retirada del shah del poder para dar paso a un gobierno democrático -o al menos eso pensaban que iba a ocurrir- se estaba radicalizando, apostando por el fin y descuidando los medios con el cual conseguirlo. Si tenían que convertir a un fallecido de cáncer en un mártir de la Revolución culpando al régimen del shah, el fallecido se convertía en mártir. El miedo también empezaba a calar en la población ante la dura represión que se estaba ejerciendo y Marjane, de nuevo como testigo, vio cómo muchas familias decidieron huir, en muchos casos a Estados Unidos y entre ellos familiares de Marjane, ante lo que se estaba aproximando: el estallido de la Revolución. Revolución que triunfó y que acabó con la huida del shah y su familia de Irán. El país lo celebró por todo lo alto pero lo que no sabían era que tras esta dictadura monárquica vendría otra religiosa. Marjane tenía que asimilar a pasos acelerados los grandes cambios que se estaban dando, con el cambio de gobierno todo símbolo de occidentalización era visto como decadente y por ello, debían ser castigados. Se implantó la obligación de llevar puesto el pañuelo a las mujeres y al igual que ellas, las calles también cambiaron de vestido: los murales y pinturas alabando al nuevo líder religioso Jomeiní y eslóganes que velaban por la sangre de los mártires se multiplicaron por la ciudad. Pero los cambios que vivió Marjane no fueron únicamente de puertas hacia fuera, donde tenía que esconder los ideales progresistas de su familia, sino que la implantación de la República Islámica de Irán supuso el resquebrajamiento del interior de la pequeña Marji. Marjane había ido cambiando progresivamente su concepción de la realidad, tal y como comentaba antes fue su padre quien le hizo ver que aquello que le contaban sobre el shah en la escuela no era cierto, que la historia la cuentan los vencedores y la pagan los vencidos. Y con la implantación del nuevo régimen uno de esos vencidos fue su tío Anouche, de nuevo encarcelado y esta vez asesinado por sus ideales, por comunista. Marjane, que hasta ese momento había mantenido una relación muy estrecha con Dios, con el que hablaba, le echó de su vida. Le habían arrebatado a uno de sus seres más queridos, habían matado a parte de su ser por pensar, por tener libertad de pensamiento. Desde ese momento Marjane se rebeló contra el mundo, aunque puertas hacia fuera tenía que hacerlo por dentro si no quería acabar como su tío. La sinceridad que aprendió con su padre se convirtió junto al sarcasmo y la ironía en su arma de defensa, algo que le valió duras reprimendas en la calle y en la escuela, incluso fue expulsada. De hecho ella vivió un desagradable episodio con las guardianas de la revolución que casi le cuesta ir ante el comité. Las guardianas tenían, y continúan teniendo en la actualidad, el poder y la influencia para juzgar quien está siguiendo la buena conducta observando los preceptos del islam y los dictados por el régimen, además de encargarse de velar por que las mujeres fueran vestidas «correctamente» según lo dictado. Marjane fue detenida por ellas por su manera de vestir, se salvó gracias a su perspicacia. 
Pero esta rebeldía se intensificó de manera exponencial cuando, ya iniciada la guerra entre Irán e Iraq (1980-1988), cayó uno de los misiles en su calle. Los Satrapi no se encontraban en casa en el momento del impacto pero sí que lo estaban sus vecinos y amigos los Baba-Levy. Marjane vio bajo los escombros de la casa cómo asomaba el brazo inerte de su amiga Neda. Neda, imposible no recordar con ese nombre el caso del asesinato durante las protestas electorales en Irán en el 2009 de la estudiante de filosofía Neda Agha-Soltan quien recibió un disparo en el pecho en plena manifestación convirtiéndose en mártir y movilizando de manera increíble a la población iraní; la violencia y la represión en Irán no son algo del pasado. Marjane fue testigo de la muerte en persona, de lo inerte que antes rebosaba vida. Marjane no podía soportarlo, se rebeló todavía más. Algo que le llevó a no callar lo que pensaba en la escuela, ya bastaba de mentiras y de falsear la verdad:

Mi tío fue encarcelado durante el régimen del Sha, ¡Pero le ejecutaron por orden del régimen islámico! Pretende hacernos creer que no hay presos políticos, cuando de los tres mil detenidos que había en tiempos del Sha se ha pasado a trescientos mil con su régimen. ¿ेCómo se atreve a mentirnos de esa manera? (Satrapi, 2010: 153).

Marjane no podía vivir en esa situación de represión, de dualidad interior, poniéndose en peligro por decir lo que pensaba, teniendo que vivir una doble vida, la que tenía que acatar y la que ella querría vivir, con libertad. Su madre tenía mucho miedo por su hija, por su sinceridad y franqueza, y no pudo evitar estallar llorando:

¿Sabes lo que le hacen a las jovencitas cuando las arrestan? ¿̇abes qué le pasó a Niloufar? La chica que conociste en casa de Khosro, el que hacía pasaportes. Sabes que, según la ley, no se puede matar a una virgen... Pues la casan con un guardián de la revolución... ¡Que la desflora antes de que la ejecuten! ¡iટ̉Sabes qué significa eso?!! Si alguien te toca un pelo... lo mato (Satrapi, 2010: 154).

Con tan sólo quince años Marjane había vivido una Revolución, había perdido a seres queridos, había visto la violencia, la muerte, la guerra. Había vivido en un mundo en el que se tienen que esconder las celebraciones -las fiestas clandestinas eran muy peligrosas- $y$ que está lleno de prohibiciones. Un mundo en el que uno no puede desarrollarse como persona sino como copia de los demás, bajo un único líder y siguiendo los mismos preceptos. De ahí la decisión de sus padres de que acabara sus estudios de secundaria en Europa. Marjane abandonó su país por un tiempo, dejó atrás los estallidos de las bombas, los muertos, los murales adoctrinantes de las calles, dejó el velo, dejó también, sus raíces y todo lo que amaba. Viena, su próximo destino. 
Y fue en Viena el lugar en el que esa dualidad interna que se empezó a gestar en Irán siendo tan sólo una niña fue en aumento. El choque cultural fue tan fuerte que sentía que si no abandonaba su identidad iraní jamás llegaría a poder integrarse: sentía que tenía que dejar de ser quien era para poder empezar de nuevo, para poder vivir en paz. Si bien los estudios fueron en un principio su refugio también se fue amparando en los amigos que iba haciendo y en los acontecimientos sociales en los que participaba, un mundo aparte del que había vivido donde ahora todo estaba permitido. Marjane quería encajar en las fiestas y en los rituales en los que participaban sus amistades -aunque fueran perjudiciales para su salud- ella no quería tener que dar explicaciones de su pasado, quería ser aceptada, dejar de tener que esforzarse el doble que los demás por encajar. Y en este contexto es en el que Marjane sufrió una verdadera crisis de identidad llegando a negar que fuera iraní, rompiendo la promesa que le hizo a su abuela de permanecer siempre íntegra consigo misma, sentía que estaba fallando a su familia y que estaba traicionando toda la confianza que habían depositado en ella.

Sin embargo, sacó fuerzas y coraje y se reivindicó como iraní y como mujer pero esa dualidad seguía latiendo todavía en algún rincón de su corazón y volvió a florecer cuando tuvo un gran desengaño amoroso, la persona en la que se había apoyado incondicionalmente en Viena. Marjane quedó tan afectada, sin más pilares a los que acudir -él había sido el único existente por largo tiempo- que, hastiada de la vida, se marchó de casa dejándose morir -inconscientemente- en el frío invernal de la calle. Despertó en el hospital: «Había pasado una revolución en la que había perdido a parte de mi familia. Había sobrevivido a una guerra que me había alejado de mi país y de mis padres... y una banal historia de amor había estado a punto de acabar conmigo» (Satrapi, 2010: 253).

Satrapi decidió volver a Irán y una vez allí, se sintió como hacía mucho que no se sentía, como en casa. Alli se puso al corriente de todo lo acontecido en su ausencia y le invadió un sentimiento de vergüenza, de haber traicionado todo lo que era, de no sentirse ni iraní ni occidental: «Pensaba que si volvía a Irán todo iría mejor. Que olvidaría los tiempos pasados... Pero mi pasado me perseguía. Mis secretos me pesaban demasiado» (Satrapi, 2010: 283). Trató sobreponerse de nuevo y superar esos sentimientos desarraigados yendo al psicólogo, pero no encontraba la solución no sabía qué podía hacer para enmendarse, para salir adelante: «Era una occidental en Irán y una Iraní en Occidente. No tenía identidad alguna. Ni siquiera sabía por qué vivía» (Satrapi, 2010: 287). Así que esta vez, conscientemente, se intentó suicidar tomando todo el bote de antidepresivos que le habían recetado, pero no falleció. Marjane Satrapi, tras su intento fallido de caer en los brazos de la muerte, tomó consciencia de sí misma: el pasado no podía cambiarlo pero tenía ante ella su presente y su futuro. Marjane fue valiente y apostó por la vida, por ella. 
Volvieron a ella las valiosas enseñanzas que había aprendido desde niña: fue sincera y franca con los demás pero sobre todo, consigo misma; apostó por su educación y estudió para pasar el concurso nacional y el test ideológico para acceder a la Universidad de Teherán y poder cursar Bellas Artes; siguió defendiendo la libertad de expresión todo lo que estuvo al alcance de su mano dentro de lo que le permitía el duro clima de represión; pero, por encima de todo, se mantuvo íntegra consigo misma.

Marjane entró en Bellas Artes en la Universidad de Teherán, lugar donde le ofrecieron interesantes proyectos y en el cual no se demoró a la hora de emprender pequeñas batallas por la igualdad de derechos de hombres y mujeres, denunciando la falta de equidad en la que salían perjudicadas las mujeres:

Usted dice que las cogullas son cortas, que los pantalones son indecentes, que no nos maquillemos, etc. Como estudiante de arte, me paso buena parte del tiempo en el taller. Necesito libertad de movimiento para poder dibujar. Un velo todavía más largo haría la tarea aún más difícil. En cuanto a los pantalones, se queja de que son demasiado anchos, aunque esconden eficazmente las formas. Y ahora que estos pantalones están de moda, le hago la pregunta: ¿ La religión defiende nuestra integridad física o simplemente se opone a la moda? No duda en hacernos reproches, cuando nuestros hermanos aquí presentes llevan todo tipo de peinados y de ropa. A veces, llevan prendas tan ceñidas que se les puede ver el cuerpo. $\dot{\imath}$ Cómo es posible que yo, como mujer, no pueda sentir nada viendo a estos fornidos señores de arriba a abajo, pero que ellos, como hombres, puedan excitarse por cinco centímetros menos de velo? (Satrapi, 2010: 312).

También fue en Teherán donde contrajo matrimonio por primera vez. La sociedad en que vivían no les permitía disfrutar de una verdadera -y real- vida en pareja a no ser que estuviesen casados -incluso de esta manera la mujer siempre tenía que rendir cuentas al marido, al padre o al hermano-, la restricción por la que tenían que pasar era muy fuerte, siempre pendientes de los y las guardianas de la revolución acechando en las calles y con miedo de que les llevaran ante el comité. Sin embargo, este matrimonio se convirtió en una cárcel para Marjane, de la cual ella misma decidió salir: no fue lo que esperaba que fuese, pero había una cosa que tenía muy clara y es que quería seguir estudiando, formándose y luchando por ella y por la igualdad. Decidió irse a Europa, quería libertad.

Marjane Satrapi, una mujer coraje que supo aceptarse a sí misma en su dualidad interna porque tal y como afirma el escritor libanés Amin Maalouf: «Lo que hace que yo sea yo, y no otro, es ese estar en las lindes de dos países, de dos o tres idiomas, de varias tradiciones culturales. Es eso justamente lo que define mi identidad. ¿Sería acaso más sincero si amputara de mí una parte de lo que soy?» (Maalouf, 2012: 11). Satrapi, mujer coraje que 
pese a vivir atrocidades y de perder el norte supo recomponerse, consiguió redescubrirse a sí misma asumiendo su pasado y su presente, asumiendo quien es, aceptándose a sí misma en la diferencia y luchando por ser íntegra consigo misma y por los derechos de los y las iraníes, aunque ahora esa batalla la lidie desde el exilio.

Todas estas vivencias y el largo camino para encontrarse a sí misma es lo que además de importantes hechos históricos ha querido plasmar en esta memoria gráfica, Persépolis. Sin embargo, no se debe olvidar que aunque el lector esté ante un documento de incalculable valor histórico y humano es una obra creada por una persona con sentimientos, con una determinada ideología y que por tanto distará de ser una obra objetiva. Por ello, entre el lector y la obra siempre debe haber una cierta distancia y un contraste con la «realidad respecto a los hechos».

Satrapi, quien no ha dejado de trabajar en el mundo del arte, ha seguido la estela de la novela gráfica. Por eso se me hace imprescindible destacar otra de sus obras, Bordados, publicada en versión original en el 2003, en la que intenta deshacer posibles estereotipos occidentales acerca de la mujer iraní. Se trata de una obra sublime en la que muestra a las mujeres iraníes en un ambiente distendido, la hora del té en la que los hombres se dirigen a echarse la siesta, y en las que ellas aprovechan para hablar de manera totalmente sincera, despreocupada, sobre la sexualidad, operaciones estéticas o el divorcio; y para ello utiliza una estética mucho más luminosa que en Persépolis. Pero la novela gráfica no ha sido el único campo en el que ha trabajado la artista pues también ha ilustrado cuentos para niños en los que de manera subliminal se encuentran sus tradiciones, cultura y un guiño hacia su país como ocurre en obras como Los monstruos tienen miedo a la luna publicada en 2001 o Ajdar en el 2002, además de haberse adentrado también en el mundo de la fábula ilustrada para adultos con El suspiro, publicado en el 2004. Y es que Marjane se ha convertido en una artista multidisciplinar ya que no se ha dedicado exclusivamente a trabajar en el ámbito de la novela gráfica sino que también ha abordado el campo del cine, visto desde los dos ángulos, como directora en la adaptación cinematográfica de Persépolis (2007) y de Pollo con ciruelas (2011), directora también de The Voices (2014) película con reparto hollywoodiense pero también actriz en The french kissers (2009) y en La bande des Jotas (2012).

Por último me gustaría indicar que en la lucha por los derechos de las mujeres iraníes y en la denuncia de la realidad del país son muchas las artistas iraníes que participan activamente. Sin embargo, quisiera destacar dos: Homa Arkani y Shadi Ghadirian. La primera transmite en sus pinturas, especialmente en su exposición Share Me (2011), esa dualidad interna en la que viven las mujeres iraníes, las diferencias tan drásticas entre puertas hacia dentro y hacia fuera del hogar, entre occidentalización y tradición. La segunda, a través de 
la fotografía denuncia la despersonalización que se ha llevado a cabo sobre la mujer. Sus obras son muy impactantes y muy claras al respecto. Unas fotografías conceptuales en las que el pañuelo es el elemento que permite identificar que lo que ella trata de mostrar son mujeres. Un pañuelo, que en el caso de sus fotografías, es lo único que permite reconocerlas.

\section{Bibliografía}

AdelKHAH, Fariba (1996): La revolución bajo el velo. Biblioteca del islam contemporáneo, Barcelona: Edicions Bellaterra.

Chute, Hillary L. (2010): Graphic women. Life narrative \& Contemporary comics, United States of America: Columbia University Press.

FarZAMniA, Nadereh (2009): Irán. De la revolución Islámica a la Revolución Nuclear. Madrid: Editorial Síntesis.

García, Santiago (2010): La novela gráfica, Bilbao: Astiberri Ediciones.

HOSPERS, John (1980): Significado y verdad en el arte, Valencia: Fernando Torres editor.

MaAlouf, Amin (2009): El desajuste del mundo. Cuando nuestras civilizaciones se agotan, Madrid: Alianza Editorial. (2012): Identidades asesinas, Madrid: Alianza Editorial.

Martín Muñoz, G., Valle Simón, B., lópez Plaza, M.Á. \& Agencia Española de Cooperación INTERNACIONAL (1998): El Islam y el mundo árabe: guía didáctica para profesores y formadores, Madrid: Agencia Española de Cooperación Internacional.

McCloud, Scott (2005): Entender el cómic. El arte invisible, Bilbao: Astiberri Ediciones.

Merinero Martín, María Jesús (2004): La República Islámica de Irán. Dinámicas sociopolíticas y relevo de las élites. Madrid: Los libros de la catarata.

Merinero Martín, María Jesús (2007): Resistencia creadora en Irán, Madrid: Biblioteca Nueva. NeYeStani, Mana (2012): Una metamorfosis iraní, Barcelona: Ediciones La Cúpula.

Riesgo Pérez-Dueño, Juan Manuel (1995): El Irán de Jomeini, Madrid: Información e Historia. Satrapl, Marjane (2010): Persépolis (volumen integral), Barcelona: Norma Editorial. (201 la): El suspiro, Barcelona: Norma Editorial. (201 1 b): Pollo con ciruelas, Barcelona: Norma Editorial. (2012a): AJDAR, Barcelona: Norma Editorial. (2012b): Bordados, Barcelona: Norma Editorial. (2012c): Los monstruos tienen miedo de la luna, Barcelona: Norma Editorial. 
SAJOO, Amyn B. (2002): Civil Society in the Muslim World: Contemporany Perspectives, I.B. London: Tauris.

SPIEGELMAN, Art (1973-1991): Maus, Barcelona: Random House Mondadori.

Recibido el 31 de enero de 2016

Aceptado el 15 de febrero de 2016 BIBLID [1 139-1219 (2016) 21: 41-57 